Article

\title{
Epigenetic Repression of miR-218 Promotes Esophageal Carcinogenesis by Targeting ROBO1
}

\author{
Miao Yang ${ }^{1}$, Ran Liu ${ }^{1}$, Xiajun Li $^{1}$, Juan Liao ${ }^{1}$, Yuepu Pu ${ }^{1}$, Enchun Pan ${ }^{2}$, Yi Wang ${ }^{2}$ and \\ Lihong Yin ${ }^{1, *}$
}

Received: 30 September 2015; Accepted: 12 November 2015; Published: 20 November 2015

Academic Editor: Martin Pichler

1 Key Laboratory of Environmental Medicine Engineering, Ministry of Education, School of Public Health, Southeast University, Nanjing 210009, China; 230129498@seu.edu.cn (M.Y.); ranliu@seu.edu.cn (R.L.); 220122800@seu.edu.cn (X.L.); 230129495@seu.edu.cn (J.L.); yppu@seu.edu.cn (Y.P.)

2 Huaian Center for Disease Control and Prevention, Huaian 223001, China; hypec@163.com (E.P.); wangyihuaian@163.com (Y.W.)

* Correspondence: lhyin@seu.edu.cn; Tel./Fax: +86-25-8327-2583

\begin{abstract}
R-218, consisting of miR-218-1 at 4p15.31 and miR-218-2 at 5q35.1, was significantly decreased in esophageal squamous cell carcinoma (ESCC) in our previous study. The aim of this study was to determine whether aberrant methylation is associated with miR-218 repression. Bisulfite sequencing analysis (BSP), methylation specific PCR (MSP), and 5-aza-2'-deoxycytidine treatment assay were applied to determine the methyaltion status of miR-218 in cells and clinical samples. In vitro assays were performed to explore the role of miR-218. Results showed that miR-218-1 was significantly CpG hypermethylated in tumor tissues $(81 \%, 34 / 42)$ compared with paired non-tumor tissues $(33 \%, 14 / 42)(p<0.05)$. However, no statistical difference was found in miR-218-2. Accordingly, expression of miR-218 was negatively correlated with miR-218-1 methylation status $(p<0.05)$. After demethylation treatment by 5 -aza- 2 '-deoxycytidine, there was a 2.53- and 2.40-fold increase of miR-218 expression in EC109 and EC9706, respectively. miR-218 suppressed cell proliferation and arrested cells at G1 phase by targeting $3^{\prime}$ untranslated region $\left(3^{\prime} \mathrm{UTR}\right)$ of roundabout guidance receptor 1 (ROBO1). A negative correlation was found between miR-218 and ROBO1 mRNA expression in clinical samples. In conclusion, our results support that aberrant CpG hypermethylation at least partly accounts for miR-218 silencing in ESCC, which impairs its tumor-suppressive function.
\end{abstract}

Keywords: miR-218; CpG methylation; esophageal cancer; ROBO1

\section{Introduction}

Esophageal cancer ranks eighth in cancer incidence and sixth in cancer mortality worldwide [1]. Most patients are asymptomatic until at advanced stages, resulting in poor outcomes. Accumulated studies suggest that epigenetic alterations parallel the histologic changes in the progression of this disease [2]. DNA methylation, one of the extensively-studied epigenetic modifications, represses transcription of the promoter regions in tumor suppressor genes and, therefore, inactivates these genes' expressions [3]. miRNAs, a class of non-coding small RNAs, exert a regulatory role through different downstream mRNAs by perfect or imperfect base-pairing [4]. Like protein coding genes, miRNAs could also be regulated by aberrant DNA methylation [5]. Several tumor-suppressive miRNAs have been reported to be silenced by CpG hypermethylation in esophageal squamous cell carcinoma (ESCC), including miR-375 [6], miR-34a [7], and miR-129-2 [8]. These studies indicate that DNA methylation is one of the crucial reasons for miRNAs' dysregulation in cancers. 
miR-218 captured our attention because of its potential tumor-suppressive role and the presence of dense CpG islands in the promoter regions shared with its host genes. In our previous study, miR-218 was identified to be down-regulated in 128 pairs of ESCC tumor tissues compared with paired non-tumor tissues by miRNA microarray and RT-PCR [9]. In fact, reduced expression of miR-218 was also reported in gastric cancer [10], nasopharyngeal cancer [11], and colon cancer [12]. These studies indicate that miR-218 may function as a tumor suppressor gene. As an intronic miRNA, miR-218 is supposed to be excised from the same primary transcript and co-regulated with its host genes, SLIT2 and SLIT3 [13,14]. SLIT2 and SLIT3 are commonly found to be silenced by aberrant DNA hypermethylation in promoter regions in cancers $[15,16]$. Thus, miR-218 is supposed to be transcriptionally silenced by aberrant DNA methylation under the same regulatory mechanism. We speculate that the loss of miR-218 in ESCC is a result of CpG islands' hypermethylation in promoter regions.

In this study, we assessed the methylation status of miR-218 CpG islands in cells and clinical samples using bisulphite sequencing, methylation specific PCR, and 5-aza-2'-deoxycytidine treatment assay, and determined that miR-218 were CpG hypermethylated in ESCC. Further, we demonstrated that miR-218 inhibited cell proliferation and arrested cell cycle at G1 phase by directly targeting $3^{\prime} U T R$ of $R O B O 1$. In summary, the results indicate that repression of miR-218 plays an essential role in ESCC tumorigenesis, which is at least partly due to CpG hypermethylation.

\section{Results}

\section{1. miR-218 Repression in ESCC Is Associated with CpG Hypermethylation}

CpG islands distribution in the promoter regions of miR-218 shared with host genes are detected by CpG Island Searcher Software (Available online: http://www.uscnorris.com/ cpgislands2/cpg.aspx). Dense CpG islands are present at the position ( -760 to -212$)$ upstream to the transcription start site (TSS) in miR-218-1, and at the position $(-407$ to +117$)$ to the TSS in miR-218-2 (Figure 1). Bisulfite sequencing analyses were applied to detect the methyaltion status of CpG sites of miR-218. Results showed that both of miR-218-1 and miR-218-2 were CpG-methylated in EC109 and EC9706 (Figure 2). To further elucidate whether miR-218 is epigenetically repressed, EC109 and EC9706 cells were treated with 5-aza-2'-deoxycytidine. The expression level of miR-218 in EC109 and EC9706 were recovered accordingly by 2.53- and 2.40-fold respectively after 5-aza-CdR treatment (Figure 3).

Having confirmed that miR-218 were epigenetically silenced in ESCC cell lines, we detected the methylation status of miR-218 in a total of 42 pairs tissues and cell lines EC9706, EC109, Het-1A using methylation specific PCR. miR-218-1 was found fully CpG-methylated in both EC9706 and EC109, while unmethylated in Het-1A (Figure 4A). CPG methylation of miR-218-1 frequently occurred in 34 cancer tissues, while only 14 paired non-tumor tissues were methylated $(p<0.05)$ (Figure 4A). For miR-218-2, it was also found fully methylated in two ESCC cell lines, while semi-methylated in Het-1A (Figure 4B). However, there is no difference in miR-218-2 methylation status between tumor tissues $(69 \%, 29 / 42)$ and paired non-tumor tissues $(60 \%, 25 / 42)$ (Figure $4 \mathrm{~B})$. The results strongly indicated the hypermethylation of miR-218 was associated with ESCC.

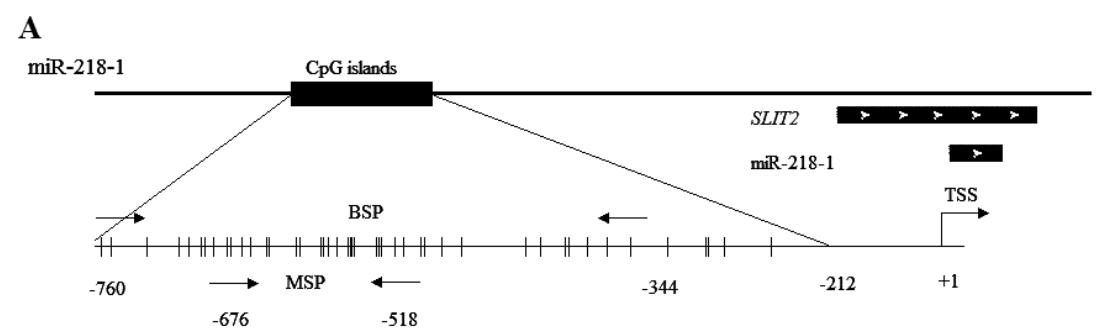

Figure 1. Cont. 
B

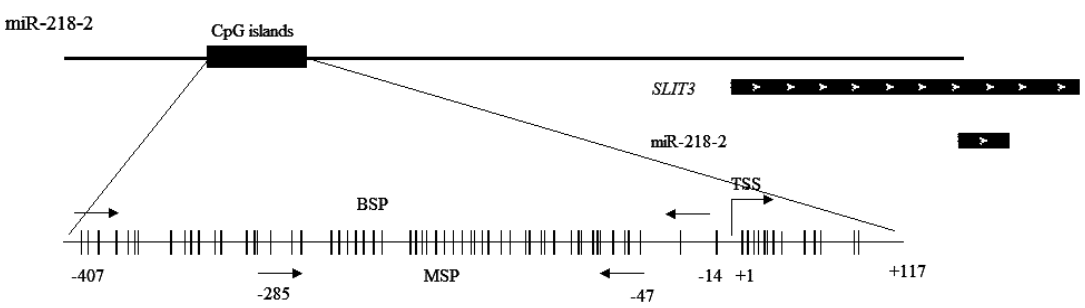

Figure 1. miR-218 is embedded within CpG islands. (A) Schematic illustration of the miR-218-1 gene embedded in the intron of SLIT2 at 4p15.31, whose promoter region is embedded within a CpG island (black box). The transcription start site is designated as +1 . The region -760 to -344 upstream of TSS was amplified for bisulfite sequencing, while -676 to -518 was amplified for methylation-specific PCR; and (B) schematic illustration of the miR-218-2 gene embedded in the intron of SLIT3 at 5q35.1, whose promoter region is also embedded within a CPG island (black box). The region -407 to -14 upstream of TSS was amplified for bisulfite sequencing, while -285 to -47 was amplified for methylation specific PCR. Vertical bars represent CpG dinucleotides. Arrows indicate the direction of gene transcription. TSS: transcription start site; BSP: bisulfite sequencing analysis; MSP: methylation specific PCR.

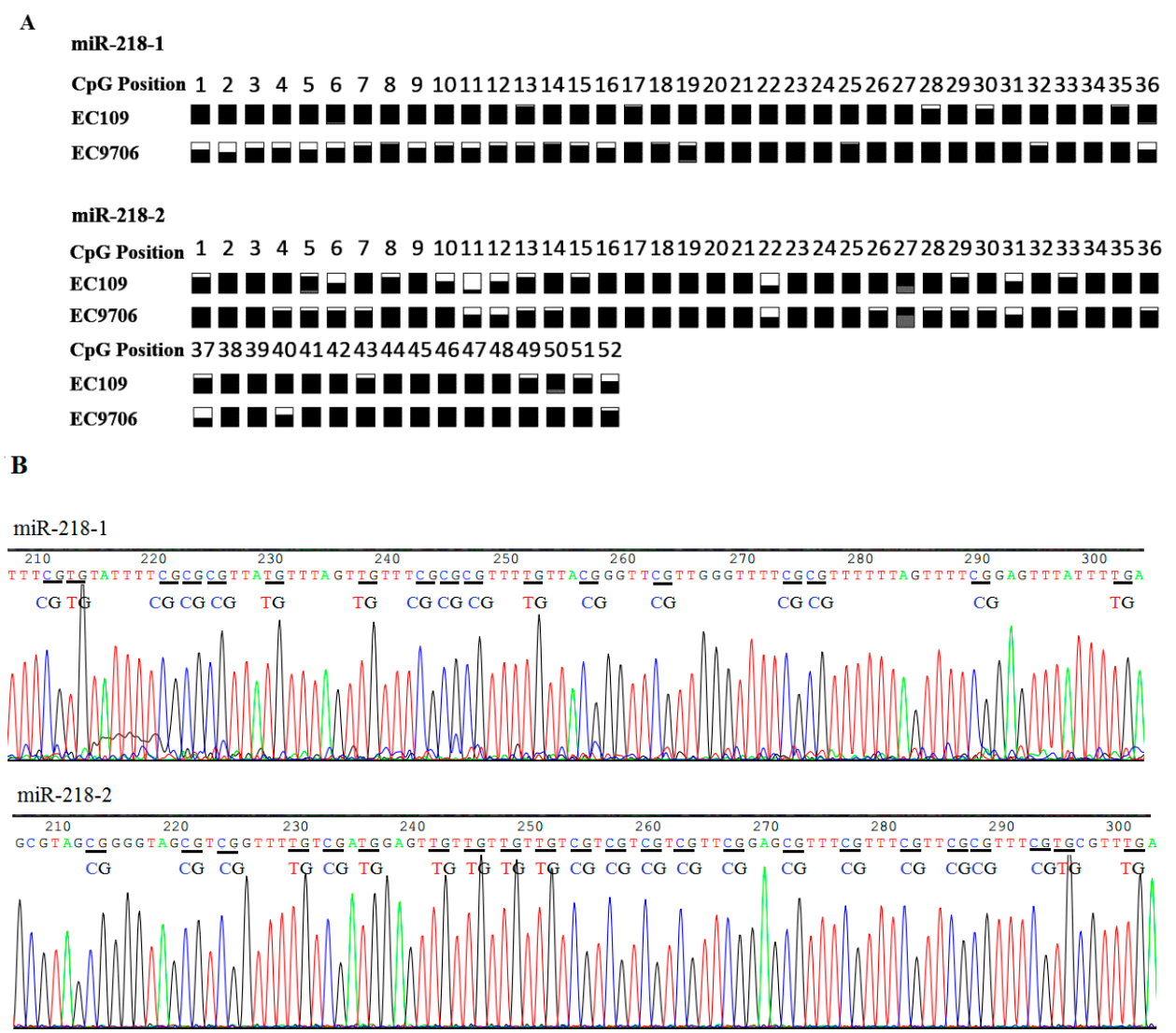

Figure 2. (A) miR-218 CpG methylation status in ESCC cell lines by bisulfite sequencing. White and black squares represent $\mathrm{CpG}$ site unmethylated and methylated, respectively. Grey squares represent $\mathrm{CpG}$ site not present. Partially squares filled with white and black represent semi-methylated $\mathrm{CpG}$. Partially squares with grey represent that $\mathrm{CpG}$ site was not present in some clones; and (B) representative electropherogram from BSP analysis of miR-218 CGI methylation status. Lines in red, green, blue and black represent T, A, C, G, respectively. "CG" and "TG" pairs are indicated by "-_ in black. ESCC: esophageal squamous cell carcinoma. 


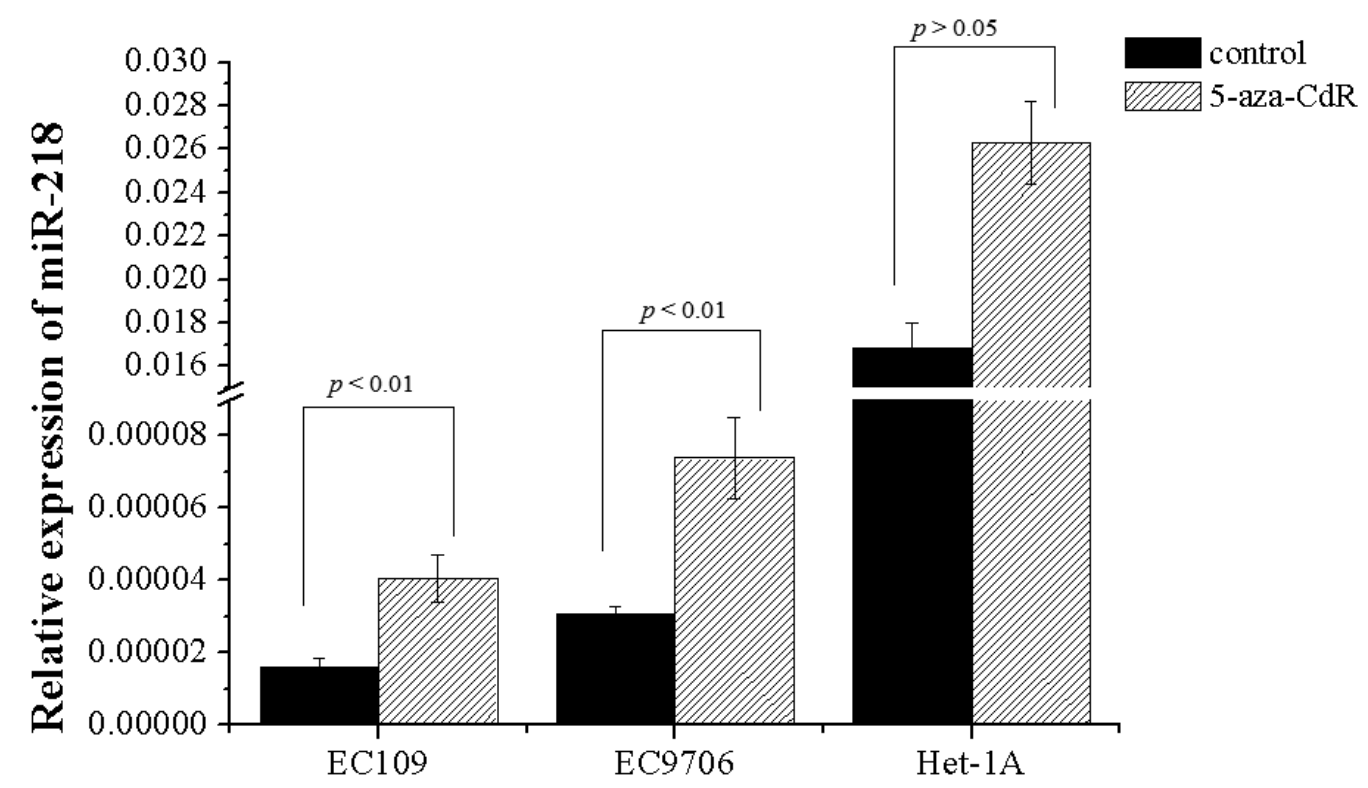

Figure 3. Effect of 5-aza-CdR treatment on miR-218 expression. ESCC cell lines were cultured in the absence or presence of 5-aza-CdR for $72 \mathrm{~h}$. miR-218 expression level in demethylation treated ESCC cells including EC109 and EC9706 were significantly increased compared with those in control cells, while no difference in Het-1A.

$\operatorname{miR}-218-1$
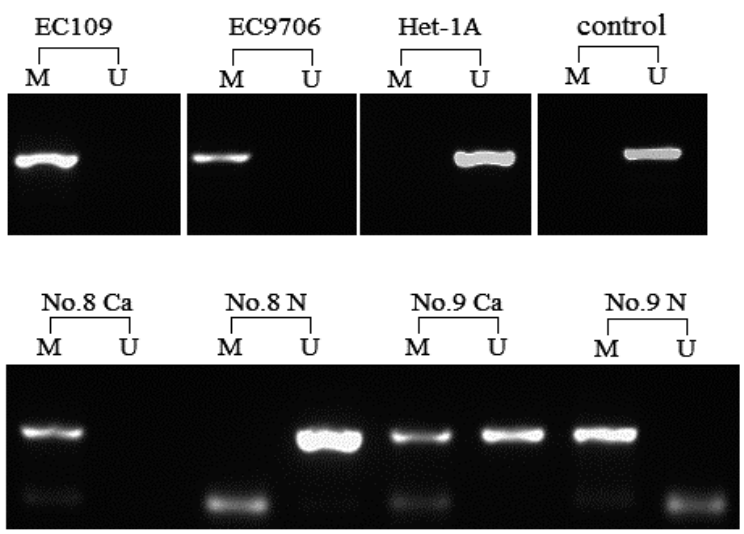

(A)
$\operatorname{miR}-218-2$
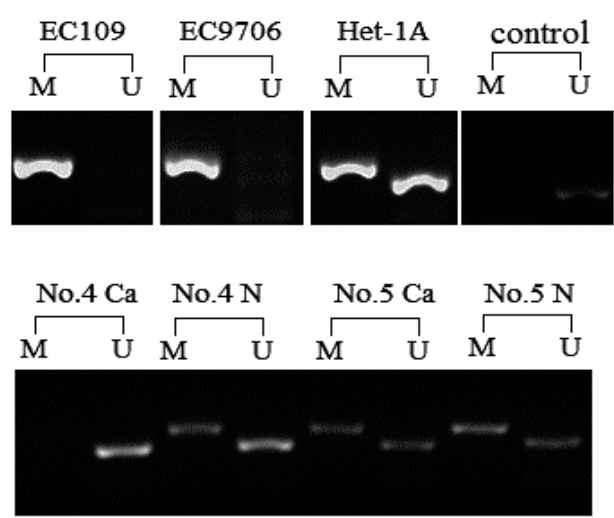

(B)

Figure 4. Detection of aberrant hypermethylation of the miR-218 by MSP analysis in cell lines and tissue samples. " $\mathrm{M}$ " represents PCR amplification using primers specific for methylated samples. " $\mathrm{U}$ " represents PCR amplification using primers specific for unmethylated samples. "Control" represents negative control from healthy human peripheral blood. "Ca" and " $\mathrm{N}$ " represent tumor tissues and paired non-tumor tissues, respectively. (A) CpG methylation of miR-218-1 in cells and tissues; and (B) CpG methylation of miR-218-2 in cells and tissues.

Further, the correlation of miR-218 CpG methylation status and miR-218 expression was assessed in 41 ESCC tumor tissues and paired non-tumor tissues. In accordance with the reduced expression of miR-218 in cancer tissues, a significant downregulation of miR-218 in miR-218-1 methylation group (including full methylation and semi-methylation) than that in unmethylation group was detected $(p<0.01)$ (Figure 5A). While there is no such correlation in miR-218-2 (Figure 5B). Moreover, miR-218 was significantly decreased in tumor tissues compared with paired non-tumor tissues 
$(p<0.05)$ (Figure 5C). Collectively, the results suggest that hypermethylation of CpG islands especially miR-218-1 CpG hypermethylation is responsible for miR-218 silencing in ESCC.
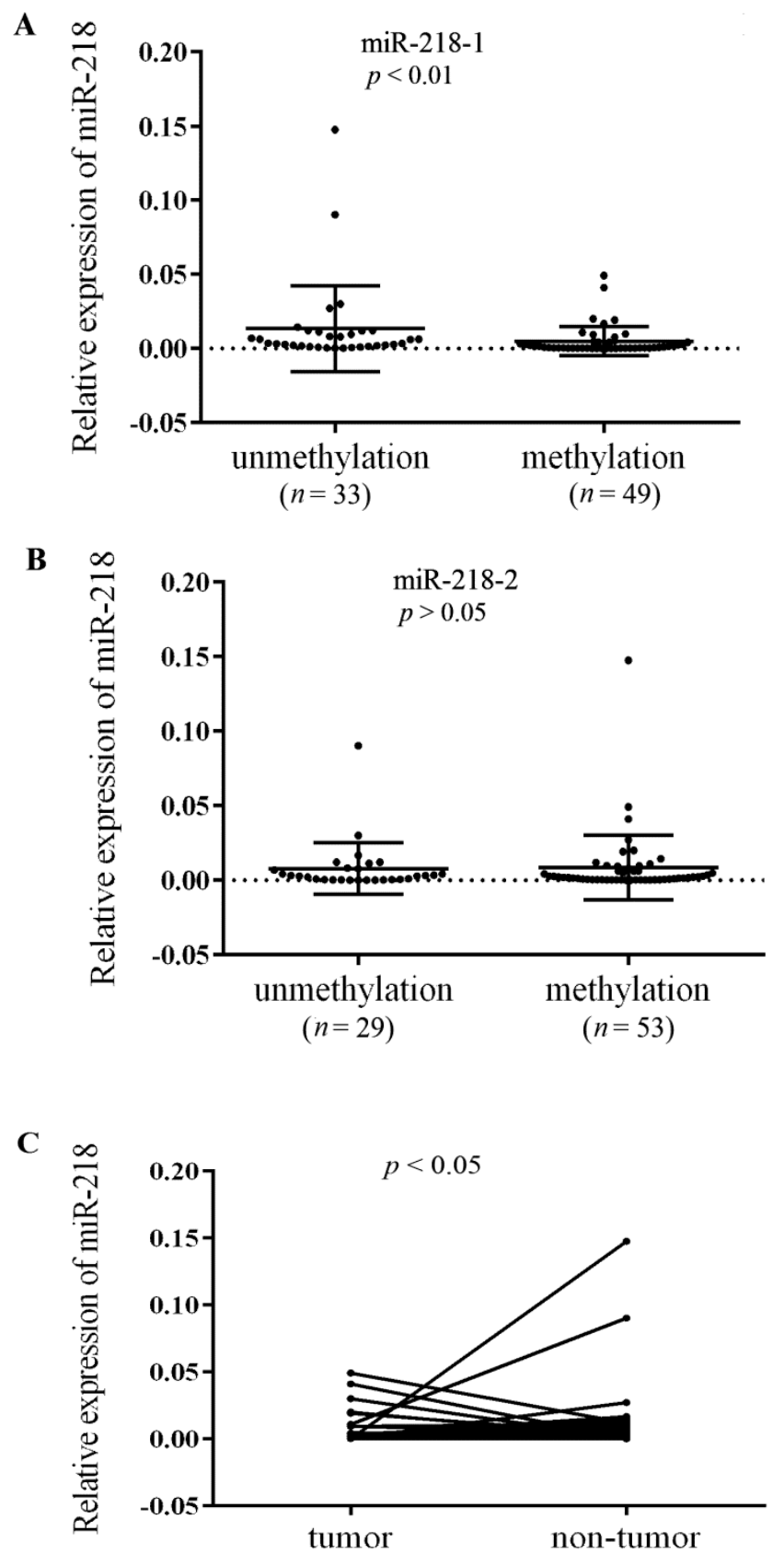

Figure 5. Aberrant DNA hypermethylation represses miR-218 expression. Expression of (A) miR-218-1; and (B) miR-218-2 were detected in methylated samples and unmethylated samples by qRT-PCR. Black lines represent error bars and mean values; (C) Expression of miR-218 in tumor tissues and paired non-tumor tissues.

\section{2. miR-218 Suppresses Cell Proliferation by Arresting Cells at G1 Phase in ESCC}

To explore the biological function of miR-218 in ESCC, gain of function analysis was performed. Transfection efficiency was detected by qRT-PCR in cells treated with miR-218 mimic and negative control $(p<0.001)$ (Figure 6A). Cells treated with miR-218 mimic displayed decreased proliferative ability measured by EdU assay $(p<0.001)$ (Figure 6B,C). Cell cycle assay was performed to investigate 
the mechanisms of miR-218 on cell growth. Cells treated with miR-218 mimic was found significantly arrested at the G1 phase $(p<0.01)$ (Figure 7). It suggests that reduced miR-218 expression might impair cell proliferation by way of disturbing the percentages of cells at each phase.

$\mathbf{A}$

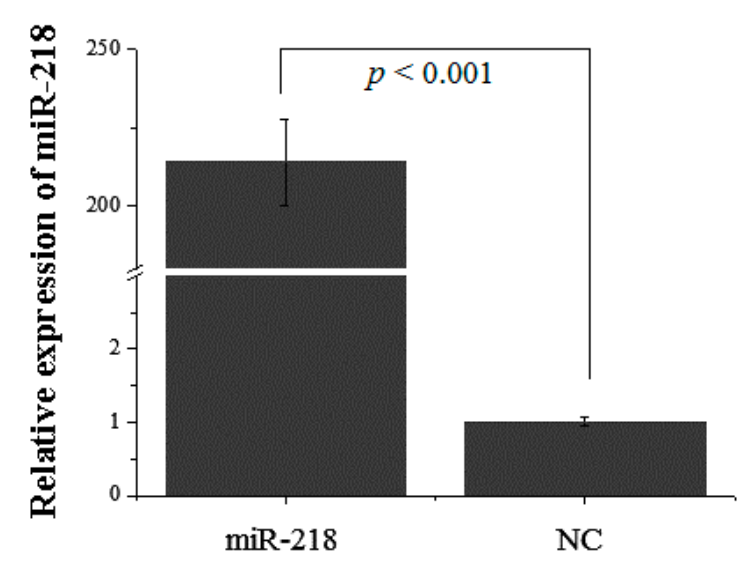

B
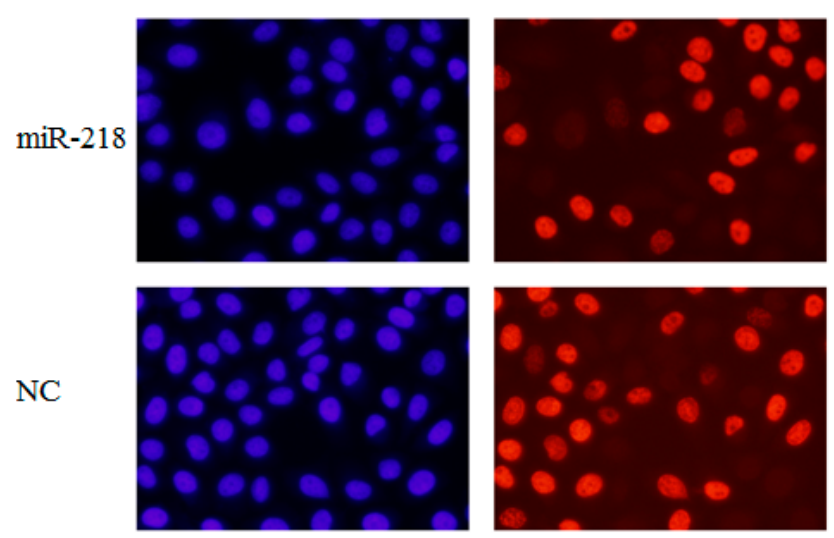

C

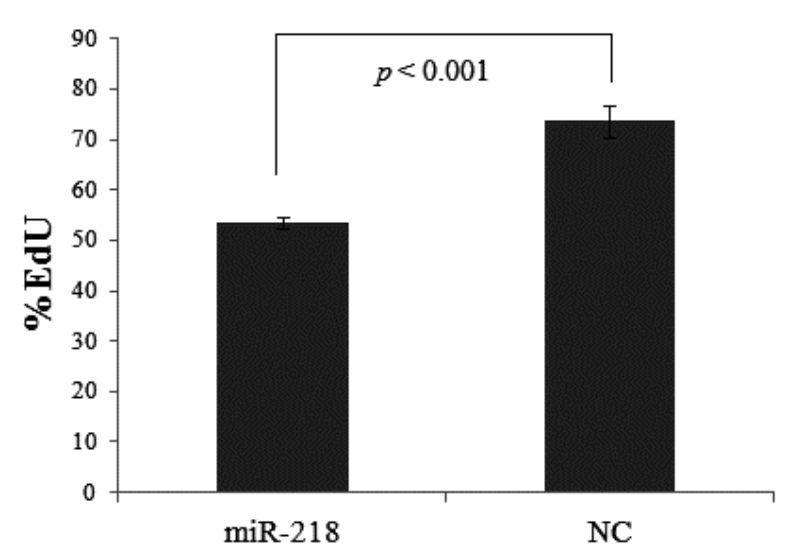

Figure 6. miR-218 suppresses cell proliferation. (A) MiR-218 expression in EC109 cells increased significantly when treated with $30 \mathrm{nM}$ miR-218 mimic compared with the negative control (NC); (B) Cells labeled in red after reaction of EdU (5-ethynyl-2'-deoxyuridine) and Apollo represent proliferative cells. Cell nuclei stained with Hoechst 33342 (blue) represent the total cells. The images are obtained by fluorescence microscope; (C) The percentage of proliferating cells was significantly increased $(p<0.001)$ in EC109 cells treated with miR-218 mimic than those in control cells. 
$\operatorname{miR}-218$

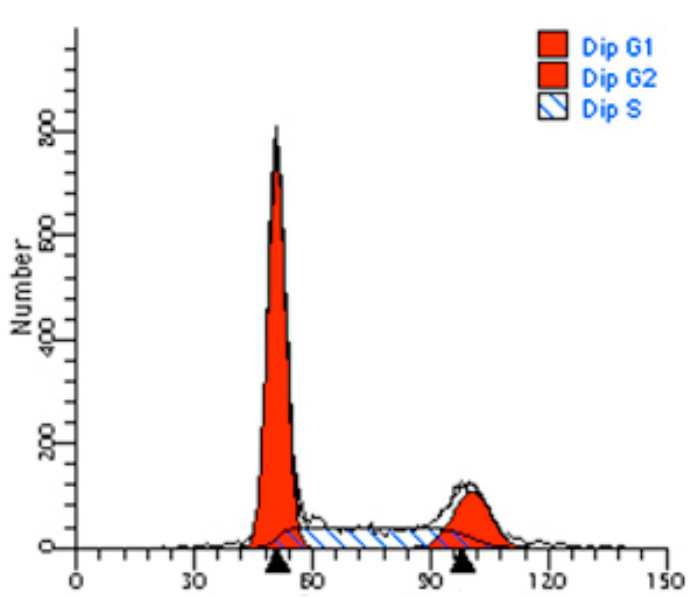

NC

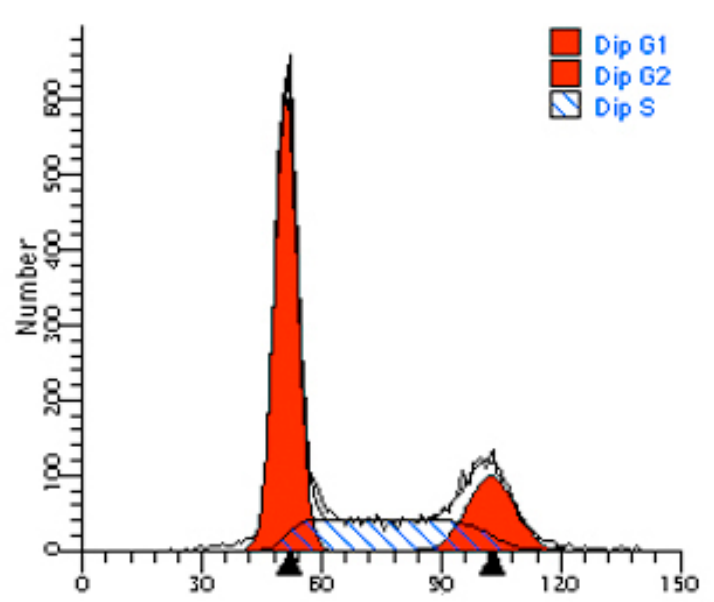

S phase

a 2 phase

a 1 phase

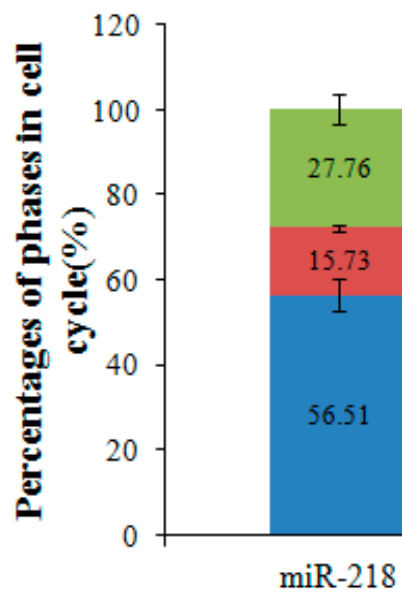

Figure 7. miR-218 arrested cell cycle at G1 phase. Flow cytometry analysis was performed to determine the constitution of cell cycle in miR-218 mimic treated cells and negative control cells. Histograms represent percentages of cells in each cell cycle phase. The cell percentage at different phases showed a cell cycle arrest in G1 phase when treated with miR-218 mimic $(p<0.01)$. NC: negative control.

\subsection{Identification of miR-218 Target in ESCC Cells}

Potential miR-218 targets were predicted using target prediction programs including miRDB, TargetScan and Pictar. ROBO1 was identified by all these prediction programs. To demonstrate that whether miR-218 directly regulates $R O B O 1$, we employed a dual-luciferase reporter assay (Figure 8A). Results showed that miR-218 significantly inhibited nearly $45 \%$ expression of constructs of $3^{\prime}$ UTR wild-type but not the mutant type, indicating that miR-218 directly regulates ROBO1 by binding to $3^{\prime} \mathrm{UTR}$ of ROBO1 $(p<0.001)$ (Figure $8 \mathrm{~B}$ ). Expression of ROBO1 mRNA in cells treated with miR-218 mimic were decreased (fold change $=3.41$ ) compared with negative control. Expression level of ROBO1 protein in miR-218 treated cells was accordingly decreased (fold change $=2.17$ ) compared with negative control (Figure 8C,D).

We further investigated the correlation between miR-218 and ROBO1 in 97 pairs of ESCC tumor tissues and non-tumor tissues using quantitative RT-PCR. With log-transformed relative expression data $\left(2^{-\Delta \Delta C t}\right)$, it turned out that miR-218 expression was negatively correlated with ROBO1 mRNA expression (spearman coefficient $=-0.258, p<0.05$ ) (Figure 9). Taken together, ROBO1 is a downstream gene of miR-218 in ESCC. 
(A)
ROBOI 3'UTR wild type
$5^{\prime}$
...UGGUUUUAAAAGCACAATC....3'
$\operatorname{miR}-218$
3' UGUACCAAUCUAGUUCGUGUU
$5^{\prime}$

ROBOI 3'UTR mutant type $5^{\prime}$

...UGGUUUUAATTCGTGTATC....3'

(B)

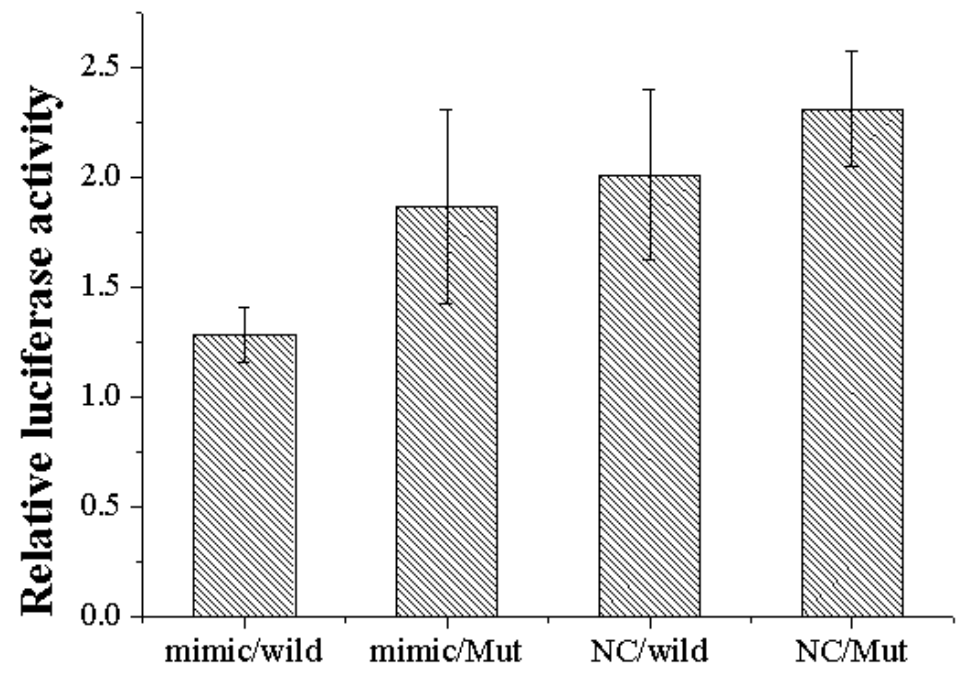

(C)

(D)

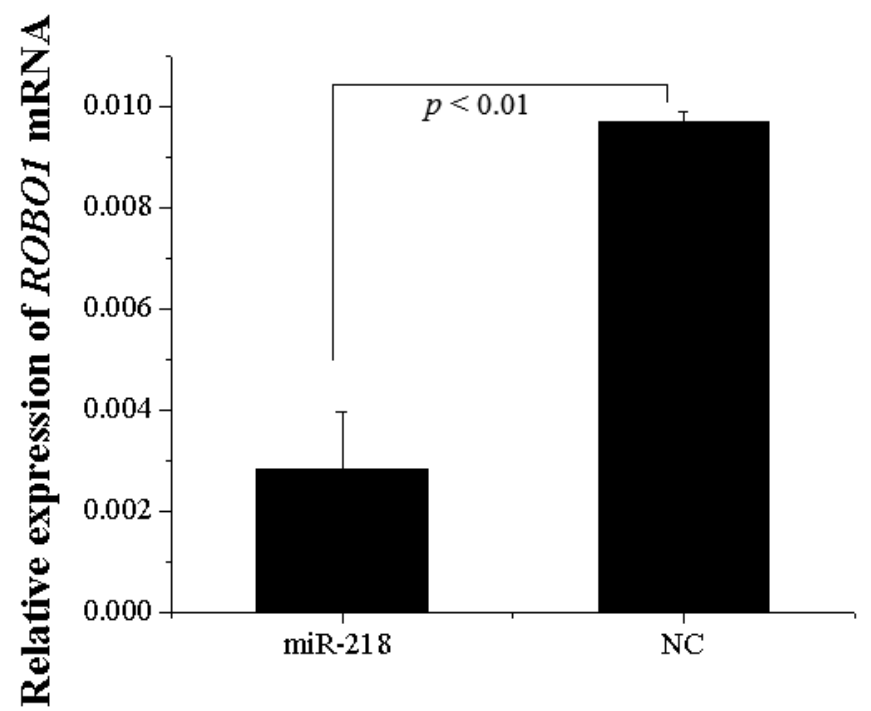

mock NC miR-218

ROBO1

$\beta$-actin

Figure 8. miR-218 targets $3^{\prime} \mathrm{UTR}$ of ROBO1. (A) The putative binding sites of miR-218 targeted the 3'UTR of ROBO1; (B) MiR-218 significantly down-regulated luciferase activity of wild type 3'UTR of ROBO1 which suggests that miR-218 directly targets the $3^{\prime} \mathrm{UTR}$ of ROBO1 $(p<0.001)$, but did not affect luciferase activity of mutant $3^{\prime} \mathrm{UTR}$ of ROBO1. WT: wild type 3'UTR of ROBO1; Mut: mutant 3'UTR of ROBO1; (C) Expression of ROBO1 mRNA was detected by qPCR in EC109 treated with miR-218 mimic and negative control; (D) ROBO1 was detected by western blot in EC109 treated with miR-218 mimic and negative control. miR-218 significantly down-regulated ROBO1 at both mRNA and protein levels. NC: negative control. 


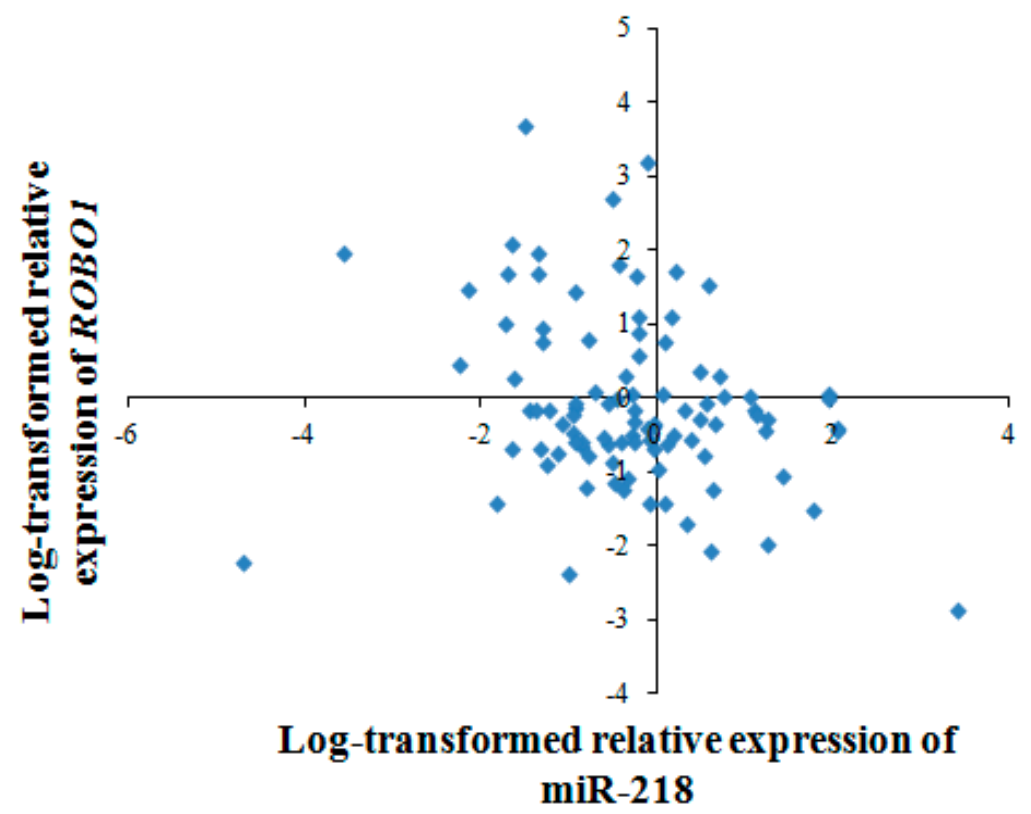

Figure 9. Association of miR-218 and ROBO1 in ESCC tissues. The scatter plot showed a significant negative correlation between miR-218 and ROBO1 (spearman coefficient $=-0.258$, $p<0.05)$. Expression levels of miR-218 and ROBO1 are normalized by U6 and $\beta$-actin, respectively. Results are expressed as log-transformed relative gene expression $\left(2^{-\Delta \Delta C t}\right)$.

\section{Discussion}

DNA methylation in CpG islands is considered to be crucial in regulating gene activity and expression. Aberrant DNA methylation, including hypermethylation of tumor suppressor genes and hypomethylation of oncogenes occurs frequently in cancers [17], and growing evidences indicate that methylation status may serve as biomarkers that are more sensitive than genetic alterations [18]. miRNAs function as oncogenes or tumor suppressor genes by regulating distinct downstream target mRNAs. However, the mechanisms on miRNA dysregulation remain unclear. Katarzyna et al. [19] showed that miR-31 is regulated epigenetically in breast cancer together with its host gene lncRNA LOC554202. Cui et al. [7] found that miR-34a is epigenetically inactivated in esophageal cancer. These studies suggest that the aberrant $\mathrm{CpG}$ methylation in miRNA promoter regions may contribute to their dysregulation in tumors [20].

In our previous study, miR-218 was found significantly decreased in ESCC by microarray and RT-PCR [9]. miR-218 is located within the introns of SLIT2 and SLIT3, whose promoter regions are frequently hypermethylated in cancers, including ovarian cancer [21], breast cancer [22,23], and cervical cancer [24]. The transcription of intronic miRNAs are deemed to coincide with their host genes, which suggests that they share the same regulatory sequences and can be regulated under the same mechanisms [25]. Intronic miR-335 is reported to be co-regulated with host gene MEST by promoter hypermethylation in hepatocellular carcinoma [26]. miR-342 was epigenetic silenced with host gene $E V L$ in colorectal cancer [27]. miR-218 is found to be frequently down-regulated in different cancers [10,28], which is consistent with our previous findings. Thus, we speculated miR-218 may be silenced by aberrant $\mathrm{CpG}$ methylation together with host genes. In this study, bisulphite sequencing and methylation-specific PCR were performed to evaluate the methyaltion status of $\mathrm{CpG}$ islands in miR-218 promoter regions. BSP analysis showed that CpG islands of both miR-218-1 and miR-218-2 were hypermethylated in ESCC cells, while unmethylated and semi-methylated, respectively, in normal esophageal epithelial cell Het-1A. MSP analysis showed that miR-218-1 displayed higher CPG methylation rations in ESCC tumor tissues than that in paired non-tumor tissues, while no such statistical difference was found in miR-218-2. More importantly, we found that miR-218-1 CpG 
hypermethylation was correlated with miR-218 expression, and miR-218 can be restored in ESCC cells with treatment of DNA demethylating agent 5-aza-2'-deoxycytidine. Therefore, it indicates that miR-218 was epigenetically regulated in ESCC. Apart from DNA methylation, other mechanisms may underline miR-218 dysregulation in ESCC. Li [28] demonstrated histone acetylation may contribute to miR-218 down-regulation in breast cancer. Interestingly, human papillomavirus type 16 is reported to reduce the expression of miR-218 in cervical carcinoma [29]. Since human papillomavirus is closely involved in the development of ESCC [30], oncogenic HPV types may play a role in miR-218 dysregulation in ESCC. However whether these mechanisms contribute to miR-218 down-regulation in ESCC needs further investigation.

Previous studies indicate that down-regulation of miR-218 seems to be a frequent event in tumorigenesis [12,31]. miR-218 exerts its tumor-suppressive function through regulation of diverse downstream target genes in different cancers. Uesugi [32] demonstrated that loss of miR-218 activated mTOR-Akt signaling pathway through direct targeting RICTOR in oral cancer. In cervical cancer, miR-218 involves in focal adhesion pathway by directly targeting LAMB3 [33]. In head and neck squamous cell carcinoma, lamin-332 is considered to be a direct downstream gene of miR-218 [34]. The role of miR-218 on cell cycle has been reported in several cancers. He [35] demonstrated miR-218 induces cell cycle arrest in the G2 phase of colon cancer cells. In breast cancer, miR-218 is found to prolong the G1 phase [28]. However, Tie [10] found miR-218 did not affect cell cycle in gastric cancer. It seems that the role of miR-218 on cell cycle varies in different cancers. And the specific roles of miR-218 in esophageal cancer have never been reported. In the present study, we found that restoring of miR-218 expression inhibited cell proliferation and arrested cell cycle at G1 phase. miR-218 is also reported to impact the migration and invasion abilities in cancers, which may be the reasons for miR-218 affecting malignant phenotypes [10,12,34]. Further, we identified ROBO1 as a direct target gene of miR-218 through $3^{\prime} \mathrm{UTR}$ reporter assay. Expression of $R O B O 1$ were decreased when miR-218 was restored both at mRNA and protein levels. Correlation analysis further revealed the loss of miR-218 was negatively correlated with up-regulation of ROBO1 in ESCC tissues and paired non-tumor tissues.

ROBO1, a member of the immunoglobulin gene superfamily and a receptor of SLIT family, is best known for the role of axon guidance in neuronal development [36-38]. Recent studies indicate that $R O B O 1$ is closely related to cancer progression. ROBO1 is up-regulated in hepatocellular carcinoma [39] and colorectal cancer [40], which indicates its oncogenic role in these cancers. Additionally, ROBO1 activates Wnt/ $\beta$-catenin signaling pathway in intestinal tumor [41], thus, functions as a cancer-promoting oncogene. Whereas $R O B O 1$ could negatively regulate motility and invasiveness of primary prostate cancer cells and, thus, functions as a tumor suppressor to inhibit the progression of prostate cancer [42]. Similar tumor suppressor function was reported in intrahepatic cholangiocarcinoma [43]. It could be concluded that $R O B O 1$ appears to have conflicting roles in different cancers. In this study, we observed that $R O B O 1$ was significantly up-regulated in ESCC cells and clinical specimen. ROBO1 mediates the downstream molecule CDC42 through $\operatorname{srGAP}$, while CDC42 is involved in JNK signaling pathway. Thus, miR-218/ROBO1 may be involved in JNK pathway through $C D C 42$, which needs further investigation.

In summary, this study describes that the loss of miR-218 in ESCC is partly due to epigenetic hypermethylation at the promoter regions. The tumor suppressive effects of miR-218 on inhibiting cell proliferation and disturbing cell cycle were identified. ROBO1 was a direct target gene of miR-218. The results support that the hypermethylation of CpG islands in miR-218 promoter regions was associated with ESCC tumorigenesis. Finally, there is great need to deeply explore the regulatory mechanisms and functions of key molecules. 


\section{Experimental Section}

\subsection{Clinical Samples}

The total of 97 patients from the First People's Hospital of Huaian were recruited between 2009 and 2010. All patients were diagnosed as primary squamous cell carcinoma of the esophagus. Tumor and paired non-tumor tissues (located $\geqslant 5 \mathrm{~cm}$ from the edge of tumor tissues) were collected and fresh frozen in an RNA Locker (Tiandz, Beijing, China) immediately after esophagectomy. Informed consent was obtained from every patient. The study was conducted according to protocols approved by the Southeast University Affiliated Zhongda Hospital Ethics Committee.

\subsection{Cell Lines and Transfection}

Human ESCC cell lines EC109, EC9706 and a human esophageal epithelial cell line Het-1A were used in this study. Cells were cultured in complete medium containing $100 \mathrm{U} / \mathrm{mL}$ each of penicillin and streptomycin (Sigma-Aldrich, Brooklyn, NY, USA) at $37^{\circ} \mathrm{C}$ with $5 \% \mathrm{CO}_{2}$.

For miR-218 mimic transfection, the miR-218 mimic (Ribobio, Guangzhou, China) was transfected into EC109 cells to transiently express miR-218. Cells $\left(2 \times 10^{5}\right.$ per well $)$ were seeded in a six-well plate with antibiotic-free medium the day before transfection, and transfected with $30 \mathrm{nM}$ miR-218 mimic and $5 \mu \mathrm{L}$ RNAiMAX (Life Technologies, Carlsbad, CA, USA) diluted by Opti-MEM medium (Life Technologies, Carlsbad, CA, USA). Transfection efficiency was determined by real-time RT-PCR after $48 \mathrm{~h}$ of incubation.

\subsection{Total RNA Isolation and Quantitative Reverse Transcription PCR}

Total RNA was extracted by using Trizol/chloroform according to protocols. After reverse transcription, real-time PCR was performed using StepOne Plus (Life Technologies, Carlsbad, CA, USA) and SYBR Green Master Mix (Toyobo, Osaka, Japan) according to the protocols. Relative expression of miR-218 was normalized against U6, while the expressions of $R O B O 1$ were normalized against $\beta$-actin. Primers sequences are described before [10].

\subsection{DNA Isolation, Bisulphite Sequencing (BSP) and Methylation Specific PCR (MSP)}

Genomic DNA was extracted using TIANamp Genomic DNA Kit (Tiangen, Beijing, China), and subjected to sodium bisulfite modification using EZ DNA Methylation Kit (Zymo, Irvine, CA, USA) as the manufacturer's protocols. Unmethylated DNA obtained from healthy human peripheral blood was used as a negative control. CpG island searcher was used to screen for $\mathrm{CpG}$ islands which meet the following criteria: CG percentage $>55 \%$; observed $\mathrm{CpG}$ /expected $\mathrm{CpG}>0.65$; length $>500$ bp. For BSP, bisulfite-modified DNA was amplified by nested PCR. The PCR products were cloned into the pGEM-T Easy vector, and 10 clones were sequenced. For MSP, each sample were amplified with methylation-specific and unmethylation-specific primers. The products were examined by $3 \%$ agarose gel electrophoresis. The presence of a band in unmethylated samples without a methylation band was defined as unmethylated. However, when a band for methylated samples was present, and absent for an unmethylation band, we defined it as methylated (or semi-methylated if both unmethylated and methylated bands were present). Primer sequences are described before $[23,44]$.

\subsection{5-Aza-2'-deoxycytidine Treatment}

5-Aza-2'-deoxycytidine (Sigma-Aldrich, Brooklyn, NY, USA) was freshly prepared in PBS and filter-sterilized for use. Cells were treated with $10 \mu \mathrm{M}$ 5-aza-2'-deoxycytidine for $72 \mathrm{~h}$, and the medium was changed every three days. Total RNA were isolated for RT-PCR analysis. 


\subsection{Cell Proliferation Assay}

Cell proliferation assay was performed using the EdU Apollo Imaging Kit (RiboBio, Guangzhou, China) as recommended in the manufacturer's protocol. EdU (5-ethynyl-20-deoxyuridine) is a thymidine analogue that can be incorporated into DNA in proliferating cells [45]. After incubating with $50 \mu \mathrm{M}$ EdU for $2 \mathrm{~h}$, cells were fixed for $30 \mathrm{~min}$ and then washed with PBS, followed by $30 \mathrm{~min}$ incubation with EdU staining. After staining, cells washed and then labeled by Hoechst 33342 for another $30 \mathrm{~min}$. Finally, cells were imaged and counted by a fluorescence microscope (FSX100, Olympus, Tokyo, Japan).

\subsection{Cell Cycle Assay}

After $48 \mathrm{~h}$ of transfection, cells were harvested and fixed at $4{ }^{\circ} \mathrm{C}$ overnight. The next day, cells were heated in $37^{\circ} \mathrm{C}$ water bath with $100 \mu \mathrm{L}$ RNase A. After $30 \mathrm{~min}$ of incubation, cells were stained with PI and analyzed by flow cytometry (Becton Dickinson, San Jose, CA, USA).

\subsection{Western Blot}

Total protein were extracted using RIPA buffer (Beyotime, Haimen, China) and protease inhibitors (Sunshinebio, Nanjing, China). $20 \mu \mathrm{g}$ protein were separated by SDS-PAGE and transferred onto polyvinylidene difluoride (PVDF) membrane. Membranes were blocked by $5 \%$ non-fat milk for $1 \mathrm{~h}$ and incubated overnight at $4{ }^{\circ} \mathrm{C}$ with primary antibodies. The next day, membranes were washed with TBST buffer and incubated with secondary antibodies conjugated to horseradish peroxidase. Immunoreactive bands were visualized and analyzed using a chemiluminescent substrate (Thermo Fisher Scientific, Grand Island, NY, USA) and automatic chemical luminescence/fluorescence image analysis system (Tanon, Shanghai, China). The antibodies used in this study were mouse monoclonal $\beta$-actin (1:800, Boster, Wuhan, China), rabbit polyclonal ROBO1 (1:200, Abcam, Cambridge, MA, USA), anti-mouse antibodies for monoclonal primary antibodies and anti-rabbit antibodies for polyclonal primary antibodies (1:5000, Santa Cruze, Dallas, TX, USA).

\subsection{3'UTR Luciferase Reporter Assay}

Human ROBO1 3'UTR were inserted into pmiR-RB miRNA reporter vector (Ribobio, Guangzhou, China). Seed-matching sequences in ROBO1 3'UTR with miR-218 (AAGCACA) were replaced by TTCGTGT as a mutant control. For luciferase assays, cells were seeded in a 24-well plate with $5 \times 10^{4}$ cells per well. After $24 \mathrm{~h}$ of incubation, cell were transfected with $100 \mathrm{ng}$ plasmids and $30 \mathrm{nM}$ miR-218 mimic or negative control. After $48 \mathrm{~h}$, cells were analyzed using Dual-Glo luciferase reporter assay (Promega, Madison, WI, USA) and Mithras LB 940 (Berthold Technologies, Bad Wildbad, Germany). Relative renilla luciferase activity was normalized to luciferase activity.

\subsection{Statistical Analysis}

Data are expressed as means \pm SD from three independent experiments. Differences in two groups were analyzed using the Student's t-test, Mann-Whitney test, McNemar test. Correlation between genes was analyzed using Spearman correlation analysis. $p<0.05$ was considered statistically significant.

Acknowledgments: This study is supported by the National Natural Science Foundation of China (Nos. 81111140396, 81072259, 81573108, 81573191), the Fundamental Research Funds for the Central Universities and Innovative Research Project for Postgraduates in Colleges of Jiangsu Province (KYZZ_0078), New Century Excellent Talents in University (NCET-13-0124), and the Fundamental Research Funds for the Central Universities. 
Author Contributions: Miao Yang and Lihong Yin conceived the experiments; Enchun Pan and Yi Wang collected clinical specimen; Miao Yang and Ran Liu designed the experiments; Miao Yang, Xiajun Li and Juan Liao performed the experiments and analyzed the data; Lihong Yin and Yuepu Pu helped with financial management and editing of the manuscript; Miao Yang wrote the paper. All authors read and approved the final manuscript.

Conflicts of Interest: The authors declare no conflict of interest.

\section{References}

1. Ferlay, J.; Soerjomataram, I.; Dikshit, R.; Eser, S.; Mathers, C.; Rebelo, M.; Parkin, D.M.; Forman, D.; Bray, F. Cancer incidence and mortality worldwide: Sources, methods and major patterns in globocan 2012. Int. J. Cancer 2015, 136, E359-E386. [CrossRef] [PubMed]

2. Komatsu, M.; Sasaki, H. DNA methylation is a key factor in understanding differentiation phenotype in esophageal squamous cell carcinoma. Epigenomics 2014, 6, 567-569. [CrossRef] [PubMed]

3. Ohtani-Fujita, N.; Fujita, T.; Aoike, A.; Osifchin, N.; Robbins, P.; Sakai, T. CpG methylation inactivates the promoter activity of the human retinoblastoma tumor-suppressor gene. Oncogene 1993, 8, 1063-1067. [PubMed]

4. Calin, G.A.; Croce, C.M. microRNA signatures in human cancers. Nat. Rev. Cancer 2006, 6, 857-866. [CrossRef] [PubMed]

5. Suzuki, H.; Maruyama, R.; Yamamoto, E.; Kai, M. DNA methylation and microRNA dysregulation in cancer. Mol. Oncol. 2012, 6, 567-578. [CrossRef] [PubMed]

6. Li, X.; Lin, R.; Li, J. Epigenetic silencing of microRNA-375 regulates pdk1 expression in esophageal cancer. Dig. Dis. Sci. 2011, 56, 2849-2856. [CrossRef] [PubMed]

7. Cui, X.; Zhao, Z.; Liu, D.; Guo, T.; Li, S.; Hu, J.; Liu, C.; Yang, L.; Cao, Y.; Jiang, J. Inactivation of miR-34a by aberrant CpG methylation in kazakh patients with esophageal carcinoma. J. Exp. Clin. Cancer Res. 2014, 33. [CrossRef] [PubMed]

8. Chen, X.; Hu, H.; Guan, X.; Xiong, G.; Wang, Y.; Wang, K.; Li, J.; Xu, X.; Yang, K.; Bai, Y. CpG island methylation status of miRNAs in esophageal squamous cell carcinoma. Int. J. Cancer 2012, 130, 1607-1613. [CrossRef] [PubMed]

9. Yang, M.; Liu, R.; Sheng, J.; Liao, J.; Wang, Y.; Pan, E.; Guo, W.; Pu, Y.; Yin, L. Differential expression profiles of microRNAs as potential biomarkers for the early diagnosis of esophageal squamous cell carcinoma. Oncol. Rep. 2013, 29, 169-176. [PubMed]

10. Tie, J.; Pan, Y.; Zhao, L.; Wu, K.; Liu, J.; Sun, S.; Guo, X.; Wang, B.; Gang, Y.; Zhang, Y. MiR-218 inhibits invasion and metastasis of gastric cancer by targeting the ROBO1 receptor. PLoS Genet. 2010, 6, e1000879. [CrossRef] [PubMed]

11. Alajez, N.M.; Lenarduzzi, M.; Ito, E.; Hui, A.B.; Shi, W.; Bruce, J.; Yue, S.; Huang, S.H.; Xu, W.; Waldron, J. $m i R-218$ suppresses nasopharyngeal cancer progression through downregulation of survivin and the SLIT2-ROBO1 pathway. Cancer Res. 2011, 71, 2381-2391. [CrossRef] [PubMed]

12. Batliner, J.; Abba, M.; Hauser, C.; Allgayer, H. miR-218 suppresses invasion and migration via inhibition of ZEB2 and N-cadherin in colon cancer. Cancer Res. 2013, 73, 4186-4186. [CrossRef]

13. Rodriguez, A.; Griffiths-Jones, S.; Ashurst, J.L.; Bradley, A. Identification of mammalian microRNA host genes and transcription units. Genome Res. 2004, 14, 1902-1910. [CrossRef] [PubMed]

14. Kim, Y.K.; Kim, V.N. Processing of intronic microRNAs. EMBO J. 2007, 26, 775-783. [CrossRef] [PubMed]

15. Qiu, H.; Zhu, J.; Yu, J.; Pu, H.; Dong, R. SLIT2 is epigenetically silenced in ovarian cancers and suppresses growth when activated. Asian Pac. J. Cancer Prev. 2011, 12, 791-795. [PubMed]

16. Zhang, C.; Guo, H.; Li, B.; Sui, C.; Zhang, Y.; Xia, X.; Qin, Y.; Ye, L.; Xie, F.A.; Wang, H. Effects of SLIT3 silencing on the invasive ability of lung carcinoma a549 cells. Oncol. Rep. 2015, 34, 952-960. [CrossRef] [PubMed]

17. Kondo, Y.; Kanai, Y.; Sakamoto, M.; Mizokami, M.; Ueda, R.; Hirohashi, S. Genetic instability and aberrant DNA methylation in chronic hepatitis and cirrhosis-A comprehensive study of loss of heterozygosity and microsatellite instability at 39 loci and DNA hypermethylation on 8 CpG islands in microdissected specimens from patients with hepatocellular carcinoma. Hepatology 2000, 32, 970-979. [PubMed]

18. Coppedè, F. Epigenetic biomarkers of colorectal cancer: Focus on DNA methylation. Cancer Lett. 2014, 342, 238-247. [CrossRef] [PubMed] 
19. Augoff, K.; McCue, B.; Plow, E.F.; Sossey-Alaoui, K. miR-31 and its host gene lncRNA LOC554202 are regulated by promoter hypermethylation in triple-negative breast cancer. Mol. Cancer 2012, 11, 5. [CrossRef] [PubMed]

20. Sato, F.; Tsuchiya, S.; Meltzer, S.J.; Shimizu, K. microRNAs and epigenetics. FEBS J. 2011, 278, 1598-1609. [CrossRef] [PubMed]

21. Dong, R.; Yu, J.; Pu, H.; Zhang, Z.; Xu, X. Frequent SLIT2 promoter methylation in the serum of patients with ovarian cancer. J. Int. Med. Res. 2012, 40, 681-686. [CrossRef] [PubMed]

22. Alvarez, C.; Tapia, T.; Cornejo, V.; Fernandez, W.; Munoz, A.; Camus, M.; Alvarez, M.; Devoto, L.; Carvallo, P. Silencing of tumor suppressor genes RASSF1A, SLIT2, and WIF1 by promoter hypermethylation in hereditary breast cancer. Mol. Carcinog. 2013, 52, 475-487. [CrossRef] [PubMed]

23. Dickinson, R.E.; Dallol, A.; Bieche, I.; Krex, D.; Morton, D.; Maher, E.R.; Latif, F. Epigenetic inactivation of SLIT3 and SLIT1 genes in human cancers. Br. J. Cancer 2004, 91, 2071-2078. [CrossRef] [PubMed]

24. Narayan, G.; Goparaju, C.; Arias-Pulido, H.; Kaufmann, A.M.; Schneider, A.; Durst, M.; Mansukhani, M.; Pothuri, B.; Murty, V.V. Promoter hypermethylation-mediated inactivation of multiple SLIT-ROBO pathway genes in cervical cancer progression. Mol. Cancer 2006, 5. [CrossRef] [PubMed]

25. Baskerville, S.; Bartel, D.P. Microarray profiling of microRNAs reveals frequent coexpression with neighboring miRNAs and host genes. RNA Publ. RNA Soc. 2005, 11, 241-247. [CrossRef] [PubMed]

26. Dohi, O.; Yasui, K.; Gen, Y.; Takada, H.; Endo, M.; Tsuji, K.; Konishi, C.; Yamada, N.; Mitsuyoshi, H.; Yagi, N. Epigenetic silencing of $m i R-335$ and its host gene MEST in hepatocellular carcinoma. Int. J. Oncol. 2013, 42, 411-418. [PubMed]

27. Grady, W.; Parkin, R.; Mitchell, P.; Lee, J.; Kim, Y.; Tsuchiya, K.; Washington, M.; Paraskeva, C.; Willson, J.; $\mathrm{Kaz}, \mathrm{A}$. Epigenetic silencing of the intronic microRNA $h s a-m i R-342$ and its host gene EVL in colorectal cancer. Oncogene 2008, 27, 3880-3888. [CrossRef] [PubMed]

28. Li, Q.; Zhu, F.; Chen, P. miR-7 and miR-218 epigenetically control tumor suppressor genes RASSF1A and claudin-6 by targeting HOXB3 in breast cancer. Biochem. Biophys. Res. Commun. 2012, 424, 28-33. [CrossRef] [PubMed]

29. Martinez, I.; Gardiner, A.; Board, K.; Monzon, F.; Edwards, R.; Khan, S. Human papillomavirus type 16 reduces the expression of microRNA-218 in cervical carcinoma cells. Oncogene 2008, 27, 2575-2582. [CrossRef] [PubMed]

30. Syrjänen, K. HPV infections and oesophageal cancer. J. Clin. Pathol. 2002, 55, 721-728. [CrossRef] [PubMed]

31. Han, G.; Fan, M.; Zhang, X. microRNA-218 inhibits prostate cancer cell growth and promotes apoptosis by repressing tpd52 expression. Biochem. Biophys. Res. Commun. 2015, 456, 804-809. [CrossRef] [PubMed]

32. Uesugi, A.; Kozaki, K.I.; Tsuruta, T.; Furuta, M.; Morita, K.I.; Imoto, I.; Omura, K.; Inazawa, J. The tumor suppressive microRNA miR-218 targets the mTOR component RICTOR and inhibits AKT phosphorylation in oral cancer. Cancer Res. 2011, 71, 5765-5778. [CrossRef] [PubMed]

33. Yamamoto, N.; Kinoshita, T.; Nohata, N.; Itesako, T.; Yoshino, H.; Enokida, H.; Nakagawa, M.; Shozu, M.; Seki, N. Tumor suppressive microRNA-218 inhibits cancer cell migration and invasion by targeting focal adhesion pathways in cervical squamous cell carcinoma. Int. J. Oncol. 2013, 42, 1523-1532. [PubMed]

34. Kinoshita, T.; Hanazawa, T.; Nohata, N.; Kikkawa, N.; Enokida, H.; Yoshino, H.; Yamasaki, T.; Hidaka, H.; Nakagawa, M.; Okamoto, Y. Tumor suppressive microRNA-218 inhibits cancer cell migration and invasion through targeting laminin-332 in head and neck squamous cell carcinoma. Oncotarget 2012, 3, 1386-1400. [CrossRef] [PubMed]

35. He, X.Q.; Dong, Y.J.; Wu, C.W.; Zhao, Z.R.; Ng, S.S.M.; Chan, F.K.L.; Sung, J.I.Y.; Yu, J. MicroRNA-218 inhibits cell cycle progression and promotes apoptosis in colon cancer by downregulating BMI1 polycomb ring finger oncogene. Mol. Med. 2012, 18, 1491-1498.

36. Kidd, T.; Brose, K.; Mitchell, K.J.; Fetter, R.D.; Tessier-Lavigne, M.; Goodman, C.S.; Tear, G. Roundabout controls axon crossing of the CNS midline and defines a novel subfamily of evolutionarily conserved guidance receptors. Cell 1998, 92, 205-215. [CrossRef]

37. Kidd, T.; Bland, K.S.; Goodman, C.S. Slit is the midline repellent for the ROBO receptor in drosophila. Cell 1999, 96, 785-794. [CrossRef]

38. Seeger, M.; Tear, G.; Ferres-Marco, D.; Goodman, C.S. Mutations affecting growth cone guidance in drosophila: Genes necessary for guidance toward or away from the midline. Neuron 1993, 10, 409-426. [CrossRef] 
39. Ao, J.Y.; Chai, Z.T.; Zhang, Y.Y.; Zhu, X.D.; Kong, L.Q.; Zhang, N.; Ye, B.G.; Cai, H.; Gao, D.M.; Sun, H.C. ROBO1 promotes angiogenesis in hepatocellular carcinoma through the Rho family of guanosine triphosphatases' signaling pathway. Tumor Biol. 2015. [CrossRef] [PubMed]

40. Gröne, J.; Doebler, O.; Loddenkemper, C.; Hotz, B.; Buhr, H.J.; Bhargava, S. ROBO1/ROBO4: Differential expression of angiogenic markers in colorectal cancer. Oncol. Rep. 2006, 15, 1437-1443. [CrossRef] [PubMed]

41. Zhang, Q.; Zhou, D.; Lei, Y.; Zheng, L.; Chen, S.; Gou, H.; Gu, Q.; He, X.; Lan, T.; Qi, C. SLIT2/ROBO1 signaling promotes intestinal tumorigenesis through src-mediated activation of the Wnt/ $\beta$-catenin pathway. Oncotarget 2015, 6, 3123-3135. [CrossRef] [PubMed]

42. Parray, A.; Siddique, H.R.; Kuriger, J.K.; Mishra, S.K.; Rhim, J.S.; Nelson, H.H.; Aburatani, H.; Konety, B.R.; Koochekpour, S.; Saleem, M. ROBO1, a tumor suppressor and critical molecular barrier for localized tumor cells to acquire invasive phenotype: Study in african-american and caucasian prostate cancer models. Int. J. Cancer 2014, 135, 2493-2506. [CrossRef] [PubMed]

43. Mano, Y.; Aishima, S.; Fukuhara, T.; Tanaka, Y.; Kubo, Y.; Motomura, T.; Toshima, T.; Iguchi, T.; Shirabe, K.; Maehara, Y. Decreased roundabout 1 expression promotes development of intrahepatic cholangiocarcinoma. Hum. Pathol. 2013, 44, 2419-2426. [CrossRef] [PubMed]

44. Dallol, A.; da Silva, N.F.; Viacava, P.; Minna, J.D.; Bieche, I.; Maher, E.R.; Latif, F. SLIT2, a human homologue of the drosophila SLIT2 gene, has tumor suppressor activity and is frequently inactivated in lung and breast cancers. Cancer Res. 2002, 62, 5874-5880. [PubMed]

45. Salic, A.; Mitchison, T.J. A chemical method for fast and sensitive detection of DNA synthesis in vivo. Proc. Natl. Acad. Sci. USA 2008, 105, 2415-2420. [CrossRef] [PubMed]

(C) 2015 by the authors; licensee MDPI, Basel, Switzerland. This article is an open access article distributed under the terms and conditions of the Creative Commons by Attribution (CC-BY) license (http://creativecommons.org/licenses/by/4.0/). 